\title{
Exploration for Applying Psychological Training in Volleyball Teaching in University
}

\author{
Jiancang Yang \\ Hubei University of Automotive Technology, Shiyan Hubei, 442002, China
}

\begin{abstract}
Keywords: University, Volleyball teaching, Psychological training, Function.
\end{abstract}
\begin{abstract}
With the development and thrive of volleyball in Chinese universities, volleyball teaching has been popular in universities all round China, volleyball teaching also obtained more and more attention from relevant teaching workers, volleyball teaching even becomes the primary task for volleyball teaching workers. While as an extremely important part of volleyball teaching, psychological training has a corresponding influence on students' volleyball learning, also has a certain positive significance on the improvement of teaching quality. This paper tries to explore and analyze the function and application of psychological training in the volleyball teaching in universities.
\end{abstract}

\section{Introduction}

Applying psychological training in volleyball teaching in universities has become an advance teaching method in recent years, it is good for strengthening and improving teaching quality. In the traditional volleyball teaching work in university, teachers paid more attention on students' physical training, they hoped to improve the whole volleyball team's practical fighting ability, but they neglected psychological training, which has an adverse influence on student athletes' strain capacity and psychological quality. Therefore, applying psychological training in volleyball teaching not only can guarantee students' physical training effect but also can promote student athletes to keep a good psychology in the game process, further to give play to their maximum advantage to guarantee corresponding success.

\section{Application status of psychological training in volleyball teaching practice in universities}

With the economic growth and people's living standard improvement, sports events also gradually gain popular development, and are widely accepted by social mass. As a kind of ball sport with a long history, volleyball naturally gains sport enthusiasts' favor, more and more people take part in volleyball exercise, volleyball even gradually develops into an important teaching subject in universities. While with the emerging of volleyball in universities, how to improving teaching results and guarantee every student can grasp a certain volleyball skills has gradually becomes a teaching difficulty for current volleyball teaching in universities, in order to overcome this difficulty, teachers should innovate volleyball teaching method, reasonably apply psychological training to implement scientific teaching guidance for students, to gradually strengthen their psychological quality to lay a foundation for good teaching quality ${ }^{[1]}$.

There is a certain difference between psychological training teaching and traditional volleyball teaching, in practical volleyball teaching practice, in addition to basic physical and skill training for athletes, teachers also should combine athletes' growth situation to carry out corresponding psychological teaching guidance, guarantee that through scientific psychological adjustment, students athletes can keep the best psychological state in the real competition, this not only can improve training effect but also can create success condition. In recent years, in China's university 
volleyball teaching, psychological training is gradually strengthened by teachers and gradually develops to corresponding key teaching points. Athletes who accepted psychological training have obvious effect on real training and competition ability, therefore, psychological training also gradually becomes an important content for university PE teaching workers.

\section{The important function of psychological training in volleyball teaching practice in universities}

\section{Can obviously improve student athletes’ psychological quality in competition}

Reasonably applying psychological training in university volleyball teaching has very important significance for improving volleyball teaching quality. Simply speaking, applying psychological training into volleyball teaching can obviously improve volleyball players' psychological quality in the competition, can cultivate their strain capacity and psychological enduring capacity, to lay foundation for athletes' professional ability in real competition, to gain a good performance.

\section{Can help students better to grasp all kinds of volleyball skills}

Reasonably applying psychological training can strengthen student players' psychological quality to promote them to give full play in the competition to make corresponding contribution for the competition $^{[2]}$. Meanwhile, reasonably applying psychological training in all kinds of teaching activities also can improve students' volleyball skill. Simply speaking, this kind of dual training method can effectively improve students' personal skill, help students grasp relevant behavior skills more quickly to help students’ volleyball skill be improved obviously.

\section{Can obviously strengthen volleyball players’ psychological quality}

Applying corresponding psychological training for students in university volleyball teaching process can strengthen and improve students' psychological enduring capacity ${ }^{[3]}$. Volleyball is a kind of competitive sport, athletes in the training process will inevitably take part in real competition, in order to gain a better performance in the competition, athletes must have good psychological enduring capacity, can deal with all kinds of emergency situation, guarantee their normal training level can be displayed in the competition. Therefore, it is necessary to apply psychological training for athletes to provide corresponding guarantee for strengthening students athletes' volleyball competition ability.

\section{Can help volleyball players reasonably arrange studying and sports in life}

Reasonable psychological training can help athletes comprehensively grasp corresponding things in life, further to combine real situation to reasonably arrange studying and sports time, on the basis of guaranteeing studying effect to take volleyball exercise to improve training effect. In this process, under the guidance of psychological training students will form right psychological concept, further to scientifically control studying and training time, which has a certain positive effect on students' comprehensive growth.

\section{Concrete measures for applying psychological training in volleyball teaching practice in universities}

It is necessary to carry out targeted psychological training for students in volleyball teaching, it is not only can help teachers complete basic teaching task and teaching goal, but also has corresponding positive influence on students' future social development. From current volleyball players' physical quality we know that most of Chinese volleyball players' psychological quality are low, which has bad influence on athletes' professional ability in real competition, it can be applied in following ways:

\section{Imaging training method}

Imaging training method, simply speaking, is to guide athletes to make corresponding sport reaction after being influenced by sports concepts, under generally situation is to be finished by image or memory for sports, it is with auto-suggestion. For Chinese university students, emotion is actually 
students' real reflection for observing relevant phenomenon in society, therefore, in order to guide students control emotion, reasonably adjust emotion, it is necessary to strengthen psychological training, help students to obtain a certain attitude experience in real sport process, further to guarantee students to act freely in competition to give full play to their own volleyball skills ${ }^{[4]}$. In real teaching activities, teachers' psychological training should be carried out from following aspects: first of all, before implementing volleyball teaching training, teachers can prepare for students and ask students to complete carefully, use the way of dynamic and static combination, before formal training, teachers ask students to repeat actions then guide students into the natural quiet state, guarantee following learning gain a good performance. Secondly, in concrete volleyball training process, teachers should combine students' real growth and psychological situation to apply psychological training, fully improve students studying enthusiasm, cultivate students' confident psychology, to realize teaching purpose.

\section{Visual imagery training method}

Visual imagery training method, generally speaking, is to set corresponding visual imagery teaching mode for students' volleyball learning in all stages, organizing students watch volleyball training videos and volleyball player examples to help students establish a certain visual images, further to training according to relevant classical movements in their mind to transfer cognitive knowledge into individualized sports skill. From professional further analysis we can see that image is the most real reflection for exterior information, it is with obvious intuition, therefore, teachers establish visual images for students by virtue of multiple medias can deepen students' cognition and understanding for relevant knowledge. For example, in the training process of "on-hand serve", teachers should combine multiple media equipment to play corresponding video for students to explain this movement. After students forming initial understanding on relevant movements, teachers then organize students to carry out specific practice, combine video teaching content to play movement to improve teaching effect. After students finishing basic training of skill movements, teachers should showed students relevant movements again, help students form deep cognition to obviously improve teaching effect.

\section{Psychological training methods}

Specifically speaking, psychological training method is a kind of method that make daily training close to real competition, in university volleyball teaching training, teachers use visual imagery training to help students establish corresponding images in brain, they need more effective teaching guidance, to help students form a deeper psychological image. Concrete operation can be implement from following aspects: first of all, in specific volleyball training competition, teachers should guide students repeat relevant skill movements in teaching activities, meanwhile, improve teaching result through observing, analyzing and thinking to guarantee movement accuracy ${ }^{[5]}$. For example, in the training process of spike, this skill movement, teachers should guide students learn how to relax their body after the movement, and guarantee the connection and standard of the movement, after professional training to form psychological image in students' brain, further to help students replay all movements clearly in real exercise to get different result. Secondly, for movement that students made mistake in training, teachers should combine reasonable correction method and corresponding psychological training to help students correct by themselves. Normally this link need teachers to finish, that is to say, in the teaching process, in order to avoid students' wrong cognition for some movements, teachers can show students some wrong movements in advance, and explain reasons, strengthen students' psychology for wrong movements further to avoid this movement in later training, to get a better performance.

\section{Psychological suggestion}

Because psychological suggestion has a certain specificity itself, therefore, in initial volleyball teaching process, teachers should use corresponding psychological suggestion language to help students recognize the importance of learning volleyball, further to guide students implement 
teachers' teaching ideas in later teaching process to lay a foundation for strengthening learning result. Meanwhile, reasonably applying psychological suggestion method in teaching practice also can help students recognize the relationship between learning volleyball skill movements and psychological ensuring capacity, and help students analyze psychological disorder formed in the training process, guide students to go out the psychological predicament to lay foundation for cultivating students' comprehensive quality. Besides, in order to guarantee psychological training time, teachers also should combine students' real growth situation to help students overcome psychological disorder and strengthen their own psychological quality to meet students' psychological need, cased on this, teachers also should take part in relevant volleyball training with students further to improve students' confidence in real training to help them train with a positive attitude to guarantee teaching effect.

\section{Conclusion}

To sum up, psychological training has an extremely influence on strengthening China's university volleyball training, it is not only related to strengthening students' volleyball skills but also related to students' comprehensive ability, which has a corresponding function on China's university talents cultivation strategy. Therefore, university PE teachers should reasonably applying psychological training in volleyball training process, in real interpretation process guide students make clear the importance of psychological quality on volleyball sport, further to pay more attention to psychological training in later training, on the basis of improving students' comprehensive quality to obtain a better development of China's volleyball.

\section{References}

[1] Zhong Ming. Exploration on the Significance and Application of Psychological Training in University Volleyball Teaching, Contemporary Sports Technology, 2013,3(14):18-19.

[2] Ding Youpeng. The Important Position of Psychological Training in University Volleyball Teaching and Training, China Education Innovation , 2012(26):200.

[3] Hao Muchun. Exploration on the Significance and Application of Psychological Training in University Volleyball Teaching, Modern Communicative,2014(10):236-236.

[4] Xue Qingyun. Research on the Application of Psychological Training in University Volleyball Teaching and Trainin, Contemporary Sports Technology,2014,4(20):25,27.

[5] Liu Yansheng. Significance and Application of Psychological Training in University Volleyball Teaching, Oriental Enterprise Culture,2014(19):282-282. 